\title{
Addressing the Challenge of Developing a Conceptual Definition for Clinical Judgment
}

\author{
Sharon Jacobs", Lesley Wilkes, Christine Taylor, Kathleen Dixon \\ School of Nursing and Midwifery, Western Sydney University, Australia
}

Copyright $\subset 2016$ by authors, all rights reserved. Authors agree that this article remains permanently open access under the terms of the Creative Commons Attribution License 4.0 International License

\begin{abstract}
Critical thinking, clinical reasoning, clinical decision making and clinical judgment, are used interchangeably in nursing literature. This presents a problem for nurses educating students to develop their clinical judgement. This paper reports on an integrative review undertaken to uncover whether it is feasible to continue using these concepts interchangeably. Data collection involved a search of relevant electronic databases for publications between 1980 and 2015 using such keywords as critical thinking, clinical reasoning, clinical decision making and clinical judgment. 23 papers met the inclusion criteria for the integrative review. Content analysis of the papers generated a total of 13 characteristics shared by the four concepts, which means that any one of the concepts can be used as a variable to measure changes in student nurses' thought processes.
\end{abstract}

Keywords Critical Thinking, Clinical Reasoning, Clinical Decision Making, Clinical Judgment, Concept Analysis, Integrative Review

\section{Introduction}

A conceptual definition is utilised to determine the characteristics of a concept under study by helping to refine and clarify it. This assists the researcher in formulating a clear and concise definition which can be used to measure the phenomenon under investigation (1). While conducting a research project examining the cognitive processes used by student nurses to make a clinical judgment using high fidelity simulation, the authors found many definitions in the literature that made it difficult to differentiate its meaning from critical thinking, clinical reasoning and clinical decision making. Therefore, the initial step in this project was to formulate a conceptual definition of clinical judgment which could be operationalised for the research project.

\section{Background}

The nursing process was one of the first structured decision making systems used in nursing and was discussed by Lydia Hall in the 1950s who postulated that nursing was a process nurses used in their practice (2). However, the idea that nurses needed a process to provide patient focused care was not introduced internationally until the 1970s. The nursing process is an organised, systematic and deliberate approach to nursing, where nurses progress through a series of steps from assessment to evaluation, with the aim of improving standards of nursing care, and presume a decision making process (3). The nursing process and nursing diagnosis were also introduced to integrate the four constructs of nursing which are health, patient, environment and nursing, used by a number of nursing theorists, for example, Henderson, Orem and King (4), to professionalise nursing and differentiate nursing care from medical practice (5). In the late 1970s, especially in United States of America, nursing diagnosis was incorporated into the nursing process, which was a strategy introduced to advance the professional status of nursing and utilise the description of actual or potential problems upon which nursing interventions were based (6).

The concepts of critical thinking, clinical reasoning, clinical decision making and clinical judgment are not explicit in the nursing process and nursing diagnosis. However, since the 1980s, these concepts have become the focus of research in nursing (7-10) and have become an essential component of professional accountability and competency for nursing registration in Australia (11) and other countries, such as England (12) and Canada (13). The International Council of Nurses sees critical thinking as an essential aspect of a code of ethical nursing practice (14). This focus has evolved from authors arguing that the stepwise linear approaches of the nursing process and nursing diagnosis have not gone far enough to show how nurses formulate their decisions and what thinking/cognitive processes are utilised. Consequently, the authors of this paper conducted a review of the literature to explore how the four concepts, namely, critical thinking, clinical reasoning, clinical decision making and clinical judgment, have been defined in the literature by undertaking content analysis of the characteristics attributed to each concept. 
An integrative review was chosen as the framework for the investigation of the literature in order to utilise both empirical and theoretical literature (15). The value of this type of review is that it provides for a more comprehensive and deeper understanding of the concepts than review of empirical research alone. According to Whittemore and Knafl (14), an integrative review is the only review method which allows use of material from the different perspectives of qualitative, quantitative and grey literature. An initial search of the literature conducted for this review yielded few published empirical studies; therefore, theoretical literature forms the bulk of this review. Grey literature has not been used for this review as the authors wanted to uncover how the concepts were characterised in peer reviewed literature which is most likely to be used in nursing research.

\section{Methods}

\subsection{The Search}

The literature search included a search of electronic databases and hand searching journals and reference lists (Conn et al. 2003). Electronic database searches were conducted on CINAHL, Ovid, Medline, the Cochrane Collaboration, the Johanna Briggs Institute, PubMed and Scopus. The search was limited to English full text articles, and because of an interest in understanding when these concepts in nursing first began to appear in the literature, the search was also limited to literature published between 1980 and 2015.

The search terms used were 'critical thinking' OR 'clinical reasoning' OR 'clinical decision making' OR 'clinical judgment' AND NURS*. Search alerts were set up to ensure all newly available literature was accessed. The initial search produced 6,057 articles. Once all the duplicates were excluded, the citations were filtered by screening the titles and abstracts. A total of 505 articles were found to be related to nursing and have a primary focus on critical thinking, clinical reasoning, clinical decision making or clinical judgment. Among these articles, only 23 provided a definition of one or more of the four concepts and were included as the final sample. A summary of the search strategy is depicted in Figure 1.

Five articles in the final sample were reports of research studies and were assessed for quality using the critical appraisal skills programme (CASP) tools (16). These articles met the CASP criteria related to appropriate methodology and sample, and although some of the sample sizes were small, this did not detract from the quality of definitions of the concepts. The remaining 18 articles in the final sample were theoretical and therefore the CASP tool was not applied.

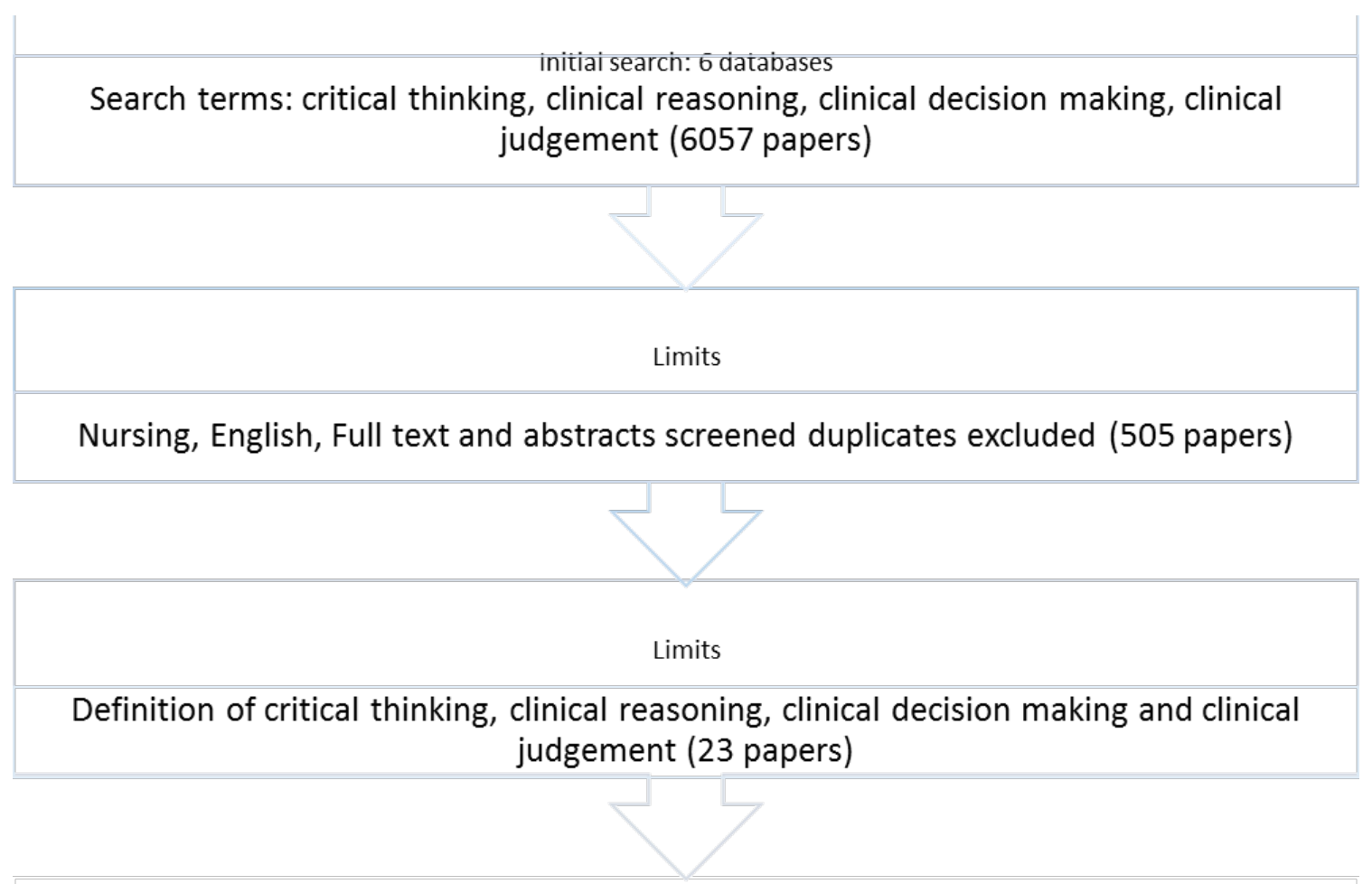

Figure 1. Literature search results 


\subsection{Analysis}

The first step in the analysis was to tabulate the definitions and method discussed in the identified articles (see Tables $1-4$ ). The next step was to extract from each article the characteristics of each of the four concepts under study, which were then abstracted and synthesised by content analysis for common characteristics and differences and tabulated in Table $5(17,18)$.

Table 1. Definitions of critical thinking in nursing

\begin{tabular}{|c|c|c|c|}
\hline 5 & Author & Definitions & Basis for definition \\
\hline (19) & $(20)$ & $\begin{array}{c}\text { Critical thinking in nursing is an essential component of } \\
\text { professional accountability and quality nursing care. } \\
\text { They also identified associated skills the person needs to } \\
\text { possess when thinking critically }\end{array}$ & $\begin{array}{c}\text { Based on research utilising the } \\
\text { Delphi technique }\end{array}$ \\
\hline 3 & $(21)$ & $\begin{array}{c}\text { Active cognitive process of logical reasoning in which } \\
\text { the individual methodically explores and analysis } \\
\text { issues, interprets complex ideas, considers all aspects of } \\
\text { a situation and/or argument and where appropriate } \\
\text { follows with prudent judgment }\end{array}$ & Theoretical discussion \\
\hline 1 & $(22)$ & $\begin{array}{c}\text { Critical thinking is an essential skill in the } \\
\text { administration of safe competent nursing care }\end{array}$ & Theoretical discussion \\
\hline 6 & $(23)$ & $\begin{array}{c}\text { Critical thinking is considered the basis for clinical } \\
\text { reasoning in professional practice and is the thought } \\
\text { processes utilised which are reflective and purposeful }\end{array}$ & Integrative review \\
\hline 2 & (24) & $\begin{array}{c}\text { Identified critical thinking as a dynamic process and } \\
\text { included the phases associated with critical thinking }\end{array}$ & Theoretical discussion \\
\hline
\end{tabular}

Table 2. Definitions of clinical reasoning in nursing

\begin{tabular}{|c|c|c|c|}
\hline & Author & Definitions & Basis of definition \\
\hline 13 & (25)_ENREF_24 & $\begin{array}{l}\text { Clinical reasoning is an essential component of } \\
\text { professional practice. It is defined as a repetitive } \\
\text { thinking process that uses both deductive and inductive } \\
\text { cognitive skills to both gather and evaluate assessment } \\
\text { data. }\end{array}$ & Literature review \\
\hline 9 & (9)_ENREF_12 & $\begin{array}{l}\text { Clinical reasoning is the process with which nurses } \\
\text { make decisions about patient care and requires specific } \\
\text { patient knowledge, understanding of the particular } \\
\text { disease processes and nursing interventions }\end{array}$ & Theoretical discussion \\
\hline 10 & (26)_ENREF_25 & $\begin{array}{l}\text { Clinical reasoning is an important component of health } \\
\text { care which focusses on the process of making decisions } \\
\text { which is pertinent to the patient's management } \\
\text { following assimilation and analysis of the data collected }\end{array}$ & Literature review \\
\hline 8 & (8)_ENREF_8 & $\begin{array}{l}\text { Clinical reasoning is considered a practice based form of } \\
\text { reasoning which requires a broad knowledge base. It } \\
\text { also requires the ability to be able to understand the } \\
\text { relevance of evidence underpinning the knowledge and } \\
\text { how it impacts on that particular patient }\end{array}$ & Theoretical discussion \\
\hline 12 & (27)_ENREF_26 & $\begin{array}{l}\text { Clinical reasoning is a context dependent way of } \\
\text { thinking and decision making in professional practice to } \\
\text { guide the actions of that professions. It permeates } \\
\text { throughout clinical practice and is considered to be at } \\
\text { the core of clinical practice and it also include reflection }\end{array}$ & Theoretical discussion \\
\hline 11 & (28)_ENREF_27 & $\begin{array}{l}\text { Clinical reasoning is a process whereby nurses seek to } \\
\text { understand the significance of the patient data collected } \\
\text { and then be able to use the collected data to plan the } \\
\text { patient's care. Clinical reasoning refers to a cyclical } \\
\text { process that nurses' move through sequentially to a final } \\
\text { decision i.e. coming to a conclusion }\end{array}$ & Theoretical discussion \\
\hline 7 & (24) & $\begin{array}{l}\text { Clinical reasoning is considered as being a very specific } \\
\text { term and refers to ways of thinking about patient issues }\end{array}$ & Theoretical discussion \\
\hline 14 & (29)_ENREF_28 & $\begin{array}{l}\text { Clinical reasoning involves applying ideas to experience } \\
\text { in order to arrive at a valid conclusion and is used to } \\
\text { describe the way a health care professional analyses and } \\
\text { understands a patient's situation and form conclusions }\end{array}$ & Theoretical discussion \\
\hline
\end{tabular}


Addressing the Challenge of Developing a Conceptual Definition for Clinical Judgment

Table 3. Definitions of clinical decision making in nursing

\begin{tabular}{|c|c|c|c|}
\hline 15 & Author & Definition & Basis for the definition \\
\hline 18 & (30)_ENREF_29 & $\begin{array}{c}\text { Decision making is a process that begins with the } \\
\text { identification of a problem and ends with evaluation of } \\
\text { the choices made and the actions taken and is based on } \\
\text { evidence }\end{array}$ & Based on a concept analysis \\
\hline 16 & (31)_ENREF_30 & $\begin{array}{r}\text { Process nurses use to gather patient information, } \\
\text { evaluate the information and make a judgment which } \\
\text { results in the provision of care. }\end{array}$ & Theoretical discussion \\
\hline 19 & (32)_ENREF_31 & $\begin{array}{c}\text { Cognitive processes involved in the formulation of the } \\
\text { patient's problems and the selection of appropriate } \\
\text { interventions }\end{array}$ & Definition based on qualitative \\
study
\end{tabular}

Table 4. Definitions of clinical judgment in nursing

\begin{tabular}{|c|c|c|c|}
\hline & Author & Clinical Judgment & Definition based on \\
\hline 22 & (9)_ENREF_12 & $\begin{array}{l}\text { Clinical judgment is an interpretation or conclusion } \\
\text { about a patient's needs, concerns or health problems } \\
\text { and/or decision to take action or not, use or modify } \\
\text { standard approaches or improvise new ones as deemed } \\
\text { appropriate by the patient's response }\end{array}$ & Theoretical discussion \\
\hline 21 & (8)_ENREF_8 & $\begin{array}{l}\text { Clinical judgment is how nurses are able to understand } \\
\text { the patient's problems, issues or concerns and to be able } \\
\text { to respond in an appropriate way. }\end{array}$ & Theoretical discussion \\
\hline 25 & (36) & $\begin{array}{l}\text { Clinical judgment is the conclusion to which a nurse } \\
\text { arrives following a process of observation, reflection } \\
\text { and analysis of observable data or available information. }\end{array}$ & Theoretical discussion \\
\hline 23 & (37) & $\begin{array}{l}\text { Clinical judgment as the interpretation of a patient's } \\
\text { needs, concerns or health problems, the decision to take } \\
\text { action or not, to decide to use established or modified } \\
\text { approaches, or develop new approaches which is } \\
\text { dependent on the patient's responses. }\end{array}$ & Theoretical discussion \\
\hline 24 & (38)_ENREF_36 & $\begin{array}{c}\text { Clinical judgment is the making of decisions which are } \\
\text { based on the evidence and on normal conjecture. } \\
\text { Clinical judgment is not linear but rather fluid as the } \\
\text { process uses a variety of ways of knowing which } \\
\text { includes the theory as well as knowledge gained from } \\
\text { experience }\end{array}$ & Theoretical discussion \\
\hline
\end{tabular}


Table 5. Comparison of the characteristics of the four concepts

\begin{tabular}{|c|c|c|c|c|}
\hline Characteristic of definition & $\begin{array}{c}\text { Critical thinking in } \\
\text { nursing }\end{array}$ & Critical reasoning & $\begin{array}{c}\text { Clinical decision } \\
\text { making }\end{array}$ & Clinical judgment \\
\hline Context dependent & Yes $(2,3,4)$ & Yes $(7,8,9,10,11,12,13,14)$ & $\begin{array}{c}\text { Yes } \\
(15,16,17,18,19,20) \\
\end{array}$ & $\begin{array}{c}\text { Yes } \\
(21,22,13,24,25)\end{array}$ \\
\hline $\begin{array}{c}\begin{array}{c}\text { Knowledge based on } \\
\text { experience }\end{array} \\
\end{array}$ & Yes $(5,6)$ & Yes $(8,9,10,11,14)$ & Yes $(15,19)$ & Yes $(21,22,23,24,25)$ \\
\hline Knowledge based on theory & Yes $(2,4)$ & Yes $(8,9,10,11,14)$ & Yes (19) & Yes $(21,22,23,24)$ \\
\hline $\begin{array}{c}\text { Knowledge based on practice } \\
\text { skills } \\
\end{array}$ & Yes (3) & Yes $(8,9,10,11,14)$ & Yes (19) & Yes $(21,22,23,25)$ \\
\hline Systematic process & Yes $(1,4,6)$ & Yes $(10,11,12,13)$ & Yes $(15,17)$ & Yes $(21,22,23,25)$ \\
\hline Reflective process & Yes (1) & Yes $(11,12,14)$ & Yes (15) & Yes $(22,23,25)$ \\
\hline $\begin{array}{l}\text { Pattern recognition and } \\
\text { synthesis }\end{array}$ & Yes (5) & Yes $(8,9,14)$ & Yes $(15,16)$ & Yes $(22,23,25)$ \\
\hline Cyclical process & Yes $(4,5)$ & Yes $(9,10,11,12,13,14)$ & Yes (15) & Yes $(22,23,25)$ \\
\hline $\begin{array}{c}\text { Interpretation of patient/client } \\
\text { needs }\end{array}$ & Yes (4) & Yes $(8,9,10,11,13,14)$ & Yes $(15,16,17,18,19$ & Yes $(21,22,23,24,25)$ \\
\hline $\begin{array}{c}\text { Culminates in a clinical } \\
\text { decision }\end{array}$ & Yes $(2,5)$ & Yes $(8,9,10,11,12,13,14)$ & Yes $(16,17,18)$ & Yes $(21,22,23,24,25)$ \\
\hline $\begin{array}{c}\text { Culminates in a nursing } \\
\text { management plan }\end{array}$ & Yes $(4,5)$ & Yes $(10,11)$ & Yes $(15,17,18)$ & Yes $(21,22,23,25)$ \\
\hline $\begin{array}{c}\text { Evaluation of choices made } \\
\text { and actions taken }\end{array}$ & Yes $(4,5)$ & Yes $(10,11,13)$ & Yes $(15,16,17,18)$ & Yes $(21,22,23,24,25)$ \\
\hline $\begin{array}{l}\text { Essential for safe } \\
\text { patient/client care }\end{array}$ & Yes $(1,3,4,5)$ & Yes $(8,9,10,11,12,13,14)$ & Yes $(15,16,17,18,19,20)$ & Yes $(21,22,23,24,25)$ \\
\hline
\end{tabular}

\section{Results}

All papers in the final review sample were related to nursing and described the characteristics of one or more of the four concepts. Of the 25 papers in the final sample, eighteen were theoretical discussion papers, three literature reviews, and four empirical studies. The first stage of data analysis was undertaken through a process of abstracting and synthesizing the characteristics attributed to all four concepts. At this stage, a list of 13 characteristics was developed. The second stage of analysis was a process whereby the number of papers that identified a characteristic for each concept including critical thinking, clinical reasoning, clinical decision making and clinical judgment was recorded (See Table 5).

\section{Critical Thinking in Nursing}

In a review of articles exploring research on critical thinking in nursing between 1992 and 2003, Brunt (22) found that only $50 \%$ of articles provided a conceptual definition and these arise out of educational literature. The definitions depicted in Table 1 are derived from six articles and include an integrative review of the literature (22), theoretical discussion papers $(20,21,23,24)$ and a research study based on a Delphi technique (19). These definitions are vague and in most cases do not extend the generic educational definitions to the nursing context. The authors, however, did emphasise context dependence, clinical skills to collect data, and outcomes, which provide safe competent nursing care.

\section{Clinical Reasoning in Nursing}

The definitions shown in Table 2 were extracted from eight articles including two literature $(25,26)$, and six theoretical discussion papers $(8,9,24,27-29)$. According to the articles, clinical reasoning is viewed as essential for safe patient care and involves both experiential and formal scientific knowledge (28). While common to all the definitions, clinical reasoning in nursing is not always framed in the same way, for example, Koharchik et al (28) used the term 'using ideas' and other authors did not emphasise experience as being important (27). Most see clinical reasoning as a cyclical process with Levett-Jones et al. (12) discussing clinical reasoning as being linked clinical encounters (p.516). The exceptions were Alfaro-LeFevre (6) and Benner et al. (10) who identified clinical reasoning as a process instead of specifying it as being cyclical.

Another commonality amongst the definitions is that clinical reasoning is a process whereby the nurse interprets the patient's needs and then utilises this information in the development of a nursing management plan. Levett-Jones et al. (27) identified specific phases the nurse works through to ultimately arrive at a conclusion about the patient's condition. All the authors agree that clinical reasoning culminates in a decision regarding patient management.

\section{Clinical Decision Making in Nursing}

The definitions shown in Table 3 were extracted from six articles, including three based on theoretical discussion of ideas $(31,33,34)$, two based on a concept analysis of literature $(30,35)$ and one qualitative study $(32)$. Three of the definitions $(30,31,34)$ were more specific in describing the various stages the nurse works through to come to a decision about patient care, whereas the remaining three definitions $(32,33,35)$ provided a broader description of clinical decision making in nursing. Although the definition 
espoused by Hoffman et al (32) was broad, it identified the actual patient care during which nurses would be making decisions. The reasoning about patient care and the selection of an appropriate plan to provide the best possible outcome for the patient were common to all the definitions of clinical decision making in the literature reviewed.

\section{Clinical Judgment in Nursing}

Five papers that were theoretical discussion papers were content analysed $(8,9,36-38)$. The definitions of clinical judgment derived from the literature are presented in Table 4. This analysis showed clinical judgment is seen as a process which culminates in an action based on practical and theoretical knowledge. Phaneuf (35) specified that clinical judgment is the conclusion nurses reach at the end of the process, whereas Benner et al (10) explained that it is the understanding of the patient's problems. Victor-Chmil (37) identified that clinical judgment is made on conjecture using both intuition and experience. Lasater (36) and Tanner (12) incorporated and extended the idea of intuition and experience to include the action taken, which was modified as a result of the patient's responses.

\section{Comparison of the Characteristics of the Four Concepts}

The common characteristics derived from the literature are: 'context dependent'; 'based on practical'; 'theoretical and experiential knowledge'; 'a systematic process"' 'a reflective process'; 'pattern recognition and synthesis'; 'a cyclical process'; 'the interpretation of the patient's/client's needs'; 'making a clinical decision'; 'formulating a management plan'; 'the evaluation of plan made and actions taken'; and 'essential for safe nursing practice' (Table 5).

Importantly, this analysis has revealed that each characteristic is found in definitions of every concept. For example, the characteristic 'context dependent' is identified as a component of the definition of critical thinking in nursing in three papers, clinical reasoning in eight papers, clinical decision making in six papers and clinical judgment in five papers (See Table 5).

Overall analysis demonstrates that each of the four concepts shares the same characteristics, making it difficult, if not impossible, to differentiate between them.

\section{Discussion}

This integrative review identified 23 articles that met the inclusion criteria. It is interesting to note that the majority of the papers reviewed used the terms critical thinking, clinical reasoning, clinical decision making and clinical judgement without explicitly defining the concepts. Through extraction and synthesis of relevant data from the articles, the authors found there appeared to be uniformity in the four concepts of critical thinking, clinical reasoning, clinical decision making and clinical judgment in nursing. As only five of these articles used research to formulate definitions, there is little empirical evidence for the identified characteristics. As a result, this research was extended to include a survey of nurse scholars and nurse academics to clarify if they agree with the identified characteristics or if there are any missing.

The four concepts are used frequently in nursing discourse and in competency standards for nursing practice and registration (11-13). The lack of empirical evidence to support the conceptual definitions highlights the urgency and importance of clarifying concepts that underpin essential aspects of nursing practice. This will have a huge impact on nursing organisations and accreditation bodies globally. A global conversation may be needed to utilise only one concept to describe cognitive processes in nursing.

The nursing process and nursing diagnosis are useful tools in nursing, but are also limited in that they do not fully capture the cognitive processes nurses need to utilise to provide safe quality nursing care. The literature reveals some common characteristics shared by critical thinking, clinical reasoning, clinical decision making and clinical judgment and these are: a systematic process, reflective process, cyclical process, involving pattern recognition and synthesis, interpretation of the patient's needs, culminating in a clinical decision and nursing management plan, involving the evaluation of choices made and actions taken and being essential for safe patient care (7). Using the integrative review to differentiate between the concepts of critical thinking, clinical reasoning, clinical decision making and clinical judgment in nursing is valuable, as it has become clear that all four concepts share common characteristics. Therefore, any one of the four concepts could be used in research as a variable to determine changes in student thinking.

\section{Conclusions}

Developing a conceptual definition of clinical judgment in nursing is a challenge because its characteristics are synonymous with those of critical thinking, clinical reasoning and clinical decision making in nursing (Table 5). This has implications for nurses designing projects that examine how the cognitive process of clinical judgment can be explored in education and practice situations. Researchers need to be very clear on the characteristics of the definition in quantitative research so that the measurement of clinical judgment is clearly formulated and an appropriate tool used. In qualitative research where interview or observations may be used, the definition needs to be clear as well so that researchers can determine how student nurses or registered nurses use clinical judgment. Finally, further research is needed to confirm the characteristics of the four concepts of critical thinking, clinical reasoning, clinical decision making and clinical judgment in nursing.

\section{Acknowledgements}

The authors would like to thank Harrison Ng Chok and Dr 
Irene Chen for their assistance and editing of this paper.

\section{REFERENCES}

[1] Burns N, Grove S. Understanding nursing research. Building on evidence based practice. 5th ed. Maryland heights, USA: Elsevier Saunders; 2011.

[2] de la Cuesta C. The nursing process: from development to implementation. Journal of Advanced Nursing. 1983; $8(5): 365-71$.

[3] Rush S, Fergy S, Wells D. Care planning the role of the nurse. Nursing Times. 1996; 92(36): Supp 1 - 4.

[4] Pearson A. Nursing models in practice. Crisp J, Taylor C, Douglas C, Robreiro G, editors. Chatswood, NSW: Elsevier; 2013.

[5] Thomas P. Technological change in nurse education as a professionalisation strategy: University of Wollongong; 1996.

[6] Hogston R. Nursing diagnosis and classification systems: a position paper. Journal of Advanced Nursing. 1997; 26(3):496 - 500 .

[7] Tanner C. Critical thinking: beyond nursing process. Journal of Nursing Education. 2000; 39(8):338.

[8] Benner P, Hughes R, Sutphen M. Clinical reasoning, decision making and action: Thinking critically and clinically. In: Hughes R, editor. Patient safety and quality: An evidence based handbook for nurses. Rockville US: Healthcare Research and Quality; 2008. p. 87 - 109.

[9] Tanner C. Thinking like a nurse: A research-based model of clinical judgement in nursing. Journal of Nursing Education. 2006; 45(6):204 - 11.

[10] Staib S. Teaching and measuring critical thinking. Journal of Nursing Education. 2003; 42(11):498 - 508.

[11] Australia NaMBo. National competency standards for the registered nurse. In: Agency AHPR, editor. Australia2007.

[12] Council NaM. Standards for competence for registered nurses. London 2010 .

[13] Manitoba CoRNo. Standards of practice for Registered Nurses. Manitoba, Canada: College of Registered Nurses of Manitoba; 2012.

[14] Nurses ICo. The ICN code of ethics for nurses. Geneva2012.

[15] Whittemore R, Knafl K. The integrative review: updated methodology. Journal of Advanced Nursing. 2005;52(5):546 -53 .

[16] Unit PHR. Critical appraisal skills programme (CASP). England2007.

[17] Penrod J, Hupcey J. Enhancing methodological clarity: principle-based concept analysis. Journal of Advanced Nursing. 2005; 50(4):403 - 9.

[18] Cronin P, Ryan F, Coughlan M. Concept analysis in healthcare research. International Journal of Therapy and
Rehabilitation. 2010; 17(2):62 - 8.

[19] Scheffer B, Rubenfield M. A consensus statement on critical thinking in nursing. Journal of Nursing Education. 2000; 39(8):352 - 9 .

[20] Profetto-McGrath J. The relationship of critical thinking skills and critical thinking dispositions of baccalaureate nursing students. Journal of Advanced Nursing. 2003; 43(6):569 - 77.

[21] Lipe S, Beasley S. Critical thinking in nursing. A cognitive skills workbook. Philadelphia: Lippincott Williams \& Wilkens; 2004.

[22] Brunt B. Critical thinking in nursing: an integrated review. The Journal of Continuing Education in Nursing. 2005; 36(2):60 - 7.

[23] Dickerson PS. Nurturing critical thinkers. The Journal of Continuing Education in Nursing. 2005; 36(2):68 - 72.

[24] Alfaro-LeFevre R. Critical thinking, clinical reasoning and clinical judgement a practical approach. St Louis: Elsevier Saunders; 2013.

[25] Simmons B, Lanuza D, Fonteyn M, Hicks F, Holm K. Clinical reasoning in experienced nurses. Western Journal of Nursing Research. 2003; 25(6):701 - 19.

[26] Banning M. Clinical reasoning and its application to nursing: concepts and research studies. Nurse Education in Practice. 2008; 8: 177 - 83 .

[27] Higgs J, Jones M, editors. Clinical reasoning and clinical decision making - nature and context. 3rd Edition ed. Philadelphia: Elsevier; 2008.

[28] Levett-Jones T, Hoffman K, Dempsey J, Jeong SY-S, Noble $\mathrm{D}$, Norton CA, et al. The 'five rights' of clinical reasoning: An educational model to enhance nursing students' ability to identify and manage clinically 'at risk' patients. Nurse Education Today. 2010; 30:515 - 20.

[29] Koharchik L, Caputi L, Robb R, Culleiton. Fostering clinical reasoning in nursing students. How can instructors in practice setting impart this essential skill? AJN. 2015; 115(1):58 - 61.

[30] Matteson P, Hawkins J. Concept analysis of decision making. Nursing Forum. 1990; 25(2).

[31] White J, Nativio D, Korbot S, Engberg S. Content and process in clinical decision making by nurse practitioner. Journal of Nursing Scholarship. 1992; 24(2):153 - 8.

[32] dela Cruz F. Clinical decision-making styles of home healthcare nurses. Journal of Nursing Scholarship. 1994; 26(3): $222-6$.

[33] Hoffman K, Donoghue J, Duffield C. Decision-making in clinical nursing: investigating contributing factors. Journal of Advanced Nursing. 2004; 45(1):53 - 62.

[34] Standing M. Clinical judgement and decision making in nursing and interprofessional healthcare. Berkshire, England: McGraw Hill; 2010.

[35] Johansen M, O'Brien J. Decision making in nursing practice: A concept analysis. Nursing Forum. 2015.

[36] Clinical judgement - an essential tool in the nursing profession [Internet]. 2008. Available from: 
http://www.learningdomain.com/MEdHOME2/RESEARCH nursing/Clinical_Judgement.pdf.

[37] Lasater K. Clinical judgement: The last frontier for evaluation. Nurse Education in Practice. 2011; 11:86 - 92.
[38] Victor-Chmil J. Critical thinking versus clinical reasoning versus clinical judgement differential diagnosis. Nurse Educator. 2013; 38(1):34 - 6 . 